\title{
Novel Paradigm of Cameraless Photography: Methodology of Al-generated photographs
}

\author{
Ozan Yavuz \\ Middle East Technical University \\ Department of Music and Fine Arts, \\ 06800, Ankara, Turkey \\ ozyavuz@metu.edu.tr
}

\begin{abstract}
After the modernist period of chemigram cameraless practices, photography in the digital and post-photography moment raised some methods such as found, altered, distorted, which are called appropriation. These approaches are connected and progressively affected by experimental photography, which is also called hybrid practices using analog and digital mediums. These neoavant-garde moments are now becoming more cameraless and not witnessed by light but codes. Currently, further Al-generated photography and its background machine learning system GANs (Generative Adversarial Networks), StyleGAN and StyleGan2 create real portraits. The main issue to be addressed here is how to read these photographs, which are more analogous to reality than ever before. In this study, Deleuze's rhizomatic approach will be considered to examine the issue. The rhizomatic philosophical concept has no centre, which loses a point/channel of desire (deterritorialization) only to start along a new path like a rhizome's spread (reterritorialization). Never-ending stream of images by GANs has a very similar structure with the body without organs/images flow and the organization, but with consistency. This process of interconnectedness and extinction shows that each portrait created is linked in a rhizomatic way. Some questions will also be reconsidered in this context: Could we still mention photography, or are these just images? In both situations, what are their specificity and structure? How could it be studied with a novel methodology and paradigm?
\end{abstract}

Generative adversarial networks. Machine learning. Al. Cameraless photography. Rhizome.

\section{INTRODUCTION}

Photographic image production has historically gone through various stages and continues to evolve into a new field based on artificial intelligence (Al). This new field can also be called a new method and representation of cameraless photography. Unlike the image created using a digital or analog camera, it establishes an unmediated relationship with the subject of cameraless photography and records it in another dimension of reality. This image production method, which started with light-sensitive chemical reactions in the historical process, has recently turned into the production of artificial intelligence based on codes. Although the cameraless method of both techniques seems to be common, there are aspects that differ from each other and can sometimes be used for different purpose. Techniques, methods and representations that differed from the early periods of the history of photography with the modernist and postmodernist period have enabled the cameraless photography to be formed in different ontological structures in each period. In the current context, Al-based photography production, which has been in development for the last decade, can be seen as a new stage in which cameraless photography has come. This method, which has an almost infinite photographic image production capacity, requires the cameraless photography technique to be evaluated ontologically in a different reading area. In this context, this study will try to examine how Albased cameraless photography follows a current paradigm and with what approaches we can define it. From this point of view of the study, it will emphasize that the technical and ontological structure of Al-based photographs is close to Deleuze's rhizomatic view, and that cameraless photography has different points with the works produced in the early and modern period. 


\section{HISTORICAL PERSPECTIVE OF CAMERALESS PHOTOGRAPHY}

\subsection{Early period}

The essential tool of the photographic process is not the camera but the light-sensitive layer. - László Moholy-Nagy

Cameraless photography can basically be defined as a method that reacts directly with light, independent of the apparatus (camera obscura etc.), and is used mostly for experimental and artistic approaches. Ironically, the term photography itself does not actually describe the camera or a similar apparatus, and the real meaning of this definition is often omitted, emphasizing the necessity of an apparatus. This alternative representation of cameraless photography has led to various avant-garde productions independent of conventional camera work. In the early periods, this approach was also used for the scientific and impartial analogical production of nature, and was associated with a documentary attitude beyond the artistic approach. The official date 1839 and 1826, which is accepted as the turning point of the mainstream historical narrative that relates the production of photographic images with the camera, actually approached with a technological determinist approach and reduced the photographic image to an apparatus. From this point of view, it can be said that cameraless photography have remained in the background in the history and development of photography, regardless of the method and theoretical studies. However, it is known that photographic image production began before the first camera models on which the camera obscura formed the basis. In this context, German physicist Johann Heinrich Schulze created the cameraless image in 1727, centuries before Niepce's camera based photograph, which is actually considered to be the first photograph (Batchen 2016). The emergence of this first trial without a camera, which can be included in the broad definition of photography, is actually an important development for the emergence of a more independent, experimental and avant-garde side of photography. Towards the end of the 19th century, cameraless photography started to give its first important examples with Thomas Wedgwood's photogram, Henry Fox Talbot's photogenic drawings and Anna Atkins's cyanotype studies. In the early cameraless works, the image is obtained by the method based on the contact printing technique. These first attempts can also be described as a universal goal to reflect the reality as it is, even without a camera, and an effort to take over the representation of reality from the painting. Therefore, cameraless photography experiments in the early stages often attempt to establish an analogy with reality. The photogram studies that Fox Talbot called photogenic drawing and applied with salted paper are among the first important applications in his book Pencil of Nature (1844-1846). The 1: 1 scale relationship that the cameraless photography technique establishes with its object highlights it as an important method for scientific documentation. The cameraless fauna studies created by Talbot with contact printing give precise information about the scale of the object. Talbot also correlates cameraless photography with scientific use, using the photomicrograph technique to photograph smaller sized objects. Similarly, Anna Atkins documents the correct realities of the plants she observed with cyanotype, a kind of photogram technique, in her book Photographs of British Algae: Cyanotype Impressions from 1843 (Parr and Badger 2004). Therefore, early period cameraless photography coincided with the idea of creating an analogy of reality, which is the basic starting point of photography, and it can be said that these studies were carried out in this context. The studies that emerged in connection with the techniques used were unique, original and non-reproducible representations. In these studies, the negative method was not used and direct positive images of the objects were created. In this sense, they have produced iconic and indexical meanings (Krauss 1977).

\subsection{Modernist period}

In the 20th century modernist period, it can be seen that avant-garde movements increased the use of cameraless photography in experimental studies and photography began to separate as a unique field in art history. The 1920s, an important process for photography to gain its own independence, were the first years of modernist and avant-garde works. In 1918, Christian Schad, was the first one to intentionally use photographic processes for purely abstract artistic purposes and Batchen (2016) mentions him as the first artist to use cameraless photography as an Avant-garde field. In the same period, Man Ray's rayograms and artist from the Bauhaus ecole László MoholyNagy's photograms were the main examples of Avant-garde cameraless works. Avant-garde studies, which are out of the traditional documentary and scientific approach in order to make photography have an experimental and autonomous structure, remained in the background in mainstream photography until the 1960s. In 1956, Pierre Cordier invented the chemigram technique, transforming cameraless photography into a different language of expression. Cordier exhibited 3 studies he made in 1958 in Cologne Photokina, naming them as "ChemoPhotogramme". He theorized the technique, which he etymologically called writing with chemicals, in his article published in 1982 (Cordier 1982). Unlike other cameraless methods, Cordier used a more 
abstract, interdisciplinary, and random method in his work. Cordier (1982) makes a statement that his method is beyond photography: "The techniques are para-photographic; they are more related to engraving, painting, lithography, etc. than to photography itself. The 1960 s were the year when photography began to take its place in the art community and photography was rediscovered in conceptual and experimental fields. As Krauss notes (2005): "In the 1960s, photography moved from a merely reproductive to an independent artistic medium, which, in this new capacity, was placed alongside more traditional media". Cordier's chemigram technique causes a new boom in cameraless photography and many contemporary followers begin to form new works such as Floris Neusüss, Hiroshi Sugimoto, Christian Marclar and Alison Rossiter.

Compared to the early periods, the development of camera-free photography has continued from an iconic and index-dependent, object-related representation method to an unrepresentable form that only references itself. The Avant-garde use of camera-free photography creates a representation beyond what is visible, not as we observe daily life, but directly and unmediated contact with light and chemicals. Therefore, the relation of representation that cameraless photography establishes ontologically with reality leads to different views in this respect. Avant-garde abstract modes of production are a direct trace of its reference and even more convergent than camera photography. However, the result is abstract and nonrepresentational, and they do not coincide with objective reality, they only represent themselves. Gottfried Jäger describes this approach as concrete photography. Concrete photography is a method that the medium only references itself, away from representations and observations: "Concrete photographs are narcissistic and egocentric, they see only themselves: absolute photographs" (2005). Jäger's definition is also the definition of modernist pure photography. It creates its own reality independent of history, representations, time and other mediums. However, according to Jäger (2005), concrete photography is not an abstract photograph, because abstraction idealizes the object and makes it abstract, while concretion concretizes and objectifies an idea. Here, a form of production begins where iconic and index based representation are breaking down and the boundaries blur. According to Warburton (2011), cameraless photography represents a kind of inbetween status that depends on the index but cannot be read: "the photographer reducing captured indexical-iconic information to more abstract yet legible form, the chemigram is additive and for the most part non-figurative." It creates a disconnection with the index but on the other hand they are traces. In this way, they continue to be unique, just like in the early period cameraless photographs, but the representational relationship it establishes with the object begins to go beyond the visible reality. In the words of Barnes (2012): "Although the works may have the appearance of abstraction, they are not in any way abstracted from reality. Rather, they are a new physical reality, an original creation in themselves".

\subsection{Postmodern period}

By the 1980s, mixed approaches were used under the influence of postmodernism and digital technology, and cameraless photography was also affected by these methods. Multi and hybrid approaches of postmodernism generally used the method of appropriation, reinterpretation and ready-made materials, so these dragged the cameraless photography technique to a freer and wider area by removing it from the chemical, analogue and dark room process. The boundaries became blurred due to the methods used in the works of this period, and photography began to shift from emergence with a light to found, altered and digital representations. Early works by Bradley Rubenstein, Untitled (Girl with Puppy Dog Eyes, 1996), digitally inserted dogs' eyes into school yearbook portraits of children; Nancy Burson, Warhead I, (1982) blended the composite portraits of world leaders are some examples of postmodern cameraless photography works shows the relationship between digital technology, visual truth and conventional documentary photography. These works mainly show the postmodern approaches of loss of reality, faith, reference and uniqueness that philosophically referenced to authors Roland Barthes (Death of Author 1967), Jean-François Lyotard (Postmodern Condition 1979), Jean Baudrillard (Simulacra and Simulation 1994), and other poststructuralists. With the effect brought about by the philosophical way of thinking, it can be seen that since the 2000s, the digital application of cameraless photography has increased and the source media has changed from analog productions to found images over the Internet. Penelope Umbrico's works that appropriates images found using search engines and picture sharing websites; Anne Collier's found photographic media images; Cory Arcangel's ready-made image backgrounds of Photoshop's gradient templates; Thomas Ruff's downloaded and appropriated Jpegs and Nudes series are some examples of postmodern era and shows aesthetic of pixels, bits, voyeurism and criticizing of objective reality. More contemporary ones like David Birkin, in the Embedded (2011) series, using the photo coding language by interferes with the coding system in the digital image (jpeg) and converts the image back into visual form. 
The use of coding languages with Photoshop and other image processing programs now shows a semi-autonomous cameraless approach in this context. That is, an approach in which the artist is not completely disabled but changes the image depending on the specific software. What change shows us is a process in which the image loses its reference and index. It is a process of creation and criticism in which the relationship and origin of the photograph with its object is questioned and put under pressure as Foucault (1977) says 'What is an Author'. In a sense, this is a critical attack strategy on the accuracy of documentary photography and of visual reality in general. The strategy of cameraless photography is in line with this critical structure because it has a decentralized, off-viewfinder look that will deconstruct the ideological approach of authority. In this sense, the process of decentralization and body without organs, which will be mentioned in the next section, begins. Digital application of cameraless photography shakes the uniqueness of the photograph. The reference of the photograph turns into quasi photos, independent of the physical world, where the codes and reality change easily. In Batchen's words (2001), photography is now just a surface.

\section{NOVEL PARADIGM OF CAMERALESS PHOTOGRAPHY}

When the GANs (Generative Adversarial Networks) method was announced in 2014 (Goodfellow et al. 2014), this development was a harbinger of a turning point for photography. The coding system in the content of GANs enables artificial intelligence to produce an infinite number of photos that it has learned by thinking autonomously. The approach of this model is a new field in which artificial intelligence will develop entirely based on machine learning by detaching photography from light and chemicals. At the same time, it moves the digital photo away from the images produced by the light falling on the sensor surface, to a digital autonomous method that is completely dependent on codes. The creation of the photograph with such a production method may mean that the act of creating the image becomes even more independent from the human eye and even makes it completely disembodied (Crary 1992) for the second time and can produce the image without seeing it. This method, which completely moves away from the camera, body, light and chemical process, reveals the need to think more about what the photograph might be and its structure.

\subsection{Structure of the GAN system}

The GAN system consists of two neural networks working opposite to each other. Generator network tries to produce lifelike images. The second network, Discriminator, tries to distinguish between fake or real images. As these two networks clash with each other, the discriminator network gradually begins to better distinguish between real and fake images. Meanwhile, generator tries to produce more realistic visuals that are indistinguishable from fake. The main purpose here is to produce more realistic images by further training the generator and to enable discriminator to evaluate the resulting images as real. In order for the GANs system to do machine learning, the real data, namely photos, must be at least hundreds of thousands. The main link here is to increase the learning ability of artificial intelligence in connection with the amount of visual data and the reality of the visuals that will emerge. As the real data increases, artificial intelligence will make machine learning better and this will provide more realistic and alternative images. In the continuation of Goodfellow's work, StyleGAN (Karras et al. 2019) and then StyleGAN2 (Karras et al. 2020) by Nvidia researchers are current GANs architectures that produce realistic photographs in this field.

\subsection{Rhizome and GANs-based cameraless Photograph?}

GAN-based photography production can be seen as a step that will change both the method and the way of thinking of the cameraless photography technique and photography. In this context, the learning and production of photographs by artificial intelligence connected to the GANs system creates a different field of study than the ontological structures of previous cameraless photography techniques. Modernism and the early period cameraless photography methods came into contact with light and chemicals in physical contact, and emerged with a structure and way of thinking connected to their object. Modernism and early cameraless photography methods came into contact with light and chemicals, and emerged with a structure and way of thinking connected to their objects. In the postmodern period, due to the use of appropriation and digital photographs, the connection with the object of the image has gradually started to break. GANs, on the other hand, by breaking the direct connection with its object further, transformed this relationship into an image, a complex network where the backward reference cannot be found and the origin is lost. Therefore, it can be said that without representing the real object, a representation is created independent of it, the origin of which cannot be found and questioned.

In this context, Deleuze and Guattari's (1980) rhizome thinking model has been considered in this study to interpret GAN's method of creating photographs and the resulting meaning. Rhizome is a philosophical thought model that emerged by 
using this description given to the root systems of plants with horizontal spreading order as a metaphor in botany. Deleuze and Guattari reveal the rootless structure in the rhizome against the tree-shaped classical western philosophy of thought such as identity, unity, hierarchy, origin and evolution. Rhizome, on the other hand, is a nonhierarchical way of thinking that shows the features of being, horizontal spreading, and multiplicity. The rhizome does not have a definite beginning and end, as opposed to the tree structure having a beginning (root), hierarchically continuing and ending. The tree moves by an evolutionary structure as roots, trunk, branches, and leaves and moves along a predetermined path. Therefore, in the tree structure where all links can be associated with the root, each link proceeds by referencing the previous one, and thus the origin represents the whole structure. According to Foucault (2011), a similar origin, projection is created: "Searching for such an origin is to try to find 'what has happened before', 'the same' of an image that is completely suitable for itself."

Rhizome, on the other hand, has an originless structure that cannot be moved backwards with forked, broken and reunited spread. Therefore, it is a being that is structured in a heterogeneous state against the localized index and cannot be traced backwards. Moving away from origin, the rhizome's mode of action, which resists representation and identity, escapes coding systems, enables it to turn into a deterritorialization structure. The subject who experiences detterritorialization establishes a new structure by reterritorialization. The hierarchical order of the tree structure is similar to the order in the organs of the human body, and according to Deleuze (1980), the body is actually an organic organism coded by the hierarchical system of capitalism and the government. Such a body cannot be matched with other body types because it is closed to being, and they are bodies trapped inside itself. The body without organs, as opposed to the organic organism, is a body that is far from hierarchy, composed of undetermined and unrestricted organs. Acting with the infinite being, it reaches other bodies, intersects with them, matches and multiplies. This is the rhizome movement of the body without organs.

One of the important steps in the attempt to find the body without organs is the use of short-term memory instead of long-term memory. Deleuze (1980, p.151) says, "Substitute forgetting for anamnesis, experimentation for interpretation" to find the body without organs. For Deleuze, the rhizome represents short-term memory, while the tree-like structure represents long-term memory. Long-term memory tries to reach a certain code, identity or origin by going back to the origin, to create an identification with it. Short-term memory is open to new paths and connections to entries, exits, expansions, such as maps or sketches, rather than going to the origin: "A map has multiple entryways, as opposed to the tracing, which always comes back "to the same" (1980, p.12).

From this point of view, we can associate the concepts of rhizome and body without organs with the methodology and image generation of GAN and artificial intelligence. First of all, GAN needs a large amount of visual data in order to work. In this respect, it can be said that it is fundamentally a method without roots. For example, the portrait photos that emerged in the thispersondoesnotexist study can be evaluated in this context. In the traditional way of creating a photograph and cameraless photography, the chemical surface or digital sensor must have a direct relationship with the object, which leads us to a tree-like, form of occurrence depending on root, causation, and identity. In thispersondoesnotexist example, the method of GANs is to act with the rhizome thinking method while creating the images. While the images are being created, it does not establish an identical, root based connection with its object. Generator does not see real data at all. There is no predetermined path, move or ground to go. On the contrary, it moves freely on the surface by forming a network whose beginning and end cannot be determined in big data. It intersects with other photographs, matches with them, reproduces and forms a body without organs through rhizomatic movement. When the portrait photos are examined, the photos cannot take you to the past, remembering and origin with a Barthesian view (1981) because they are independent of time and place. The images produced by GANs bifurcate in the continuous being created by short-term memory.

Photographs created with the camera and, in part, some cameraless, emerge as an evolutionary images. This image is an organic, bodied organism. Its origin can be reached, its codes, identity can be found, and its representation can be analysed.

In the GANs method, while artificial intelligence produces new visuals, it creates a carnivalesque structure that enables all possible types of visual relationships to be intertwined without moving from a certain point (root). In this structure, images emerge as bodies without organs, with asignifying rupture and decalcomania. According to Adkins (2015), decalkomania means the transfer of existing images to another surface, based on the word "decal". Moinuddin (2019) sees the decalkomania method as a rhizome, not a simple transfer method: 'the principle of decalcomania: the rhizome operates by variation, expansion, conquest, capture and offshoots! It means it changes according to encounters'. 
In this respect, the cameraless images produced by GANs and artificial intelligence based on machine learning create debate on two issues. The first is that by separating these images from traditional methods of existence, all the connections (political and ethical) that make them up must be rethinked. Second, this new way of existence leads us to a second discussion as to whether these images are photographs or not. The role of GANs and artificial intelligence here is to change the representation method and make us believe, convince that the images created are photographs. So these images are photographs that are not photographs or photographs reproduced from photographs. What we are convinced of is that GAN's method is able to show the photographic reality without us noticing it.

\section{CONCLUSION}

Cameraless photography has reached a new stage technically and theoretically in the historical process. Artificial intelligence and machine learning show that a camera is no longer needed for image and photo production. The method, which gives its first examples over simpler examples such as portraits, animals and various objects, will gradually evolve into more complex scenes. In addition, various GANs models are also working on alternative image generation methods. Some of those are; creating new images based on a single image SinGAN (Shaham et al. 2019); and text to image, MirrorGan (Qiao et al, 2019) and Obj-Gans (Li et al., 2019) methods. What they all have in common is autonomous photographs produced by artificial intelligence without cameras, chemicals and light.

In this study, it has been discussed with the rhizome way of thinking that the images produced are photographs, but the way of its formation is far from traditional method. The images produced are far from their references, but they are still linked to physical reality, and this image formation occurs without a camera. As a result, the images we see appear as photographs and can take place as a representation of physical reality.

\section{REFERENCES}

Adkins, Brent. (2015) Deleuze and Guattari's A Thousand Plateaus: A Critical Introduction and Guide. Edinburgh University Press, Edinburgh.

Barnes, Martin. (2012) Shadow Catchers: Cameraless Photography. Perseus Distribution Services, London.

Barthes, Roland, (1977) [1967] 'Death of the Author,' Image, Music and Text, transl. Stephen Heath. Hill \& Wang, New York.
Barthes, Roland. (1981). Camera lucida: Reflections on photography (1st American ed.). Hill and Wang.

Baudrillard, (1994) Simulacra and Simulation, Sheila Faria Glaser (trans.), University of Michigan Press, Ann Arbor.

Batchen, Geoffrey. (2001) "Carnal Knowledge." Art Journal 60:1, 21-23. Print.

Batchen, Geoffrey. (2016) Emanations: the art of the cameraless photograph. DelMonico Books, Munich London New York.

Cordier, Pierre. (1982) Chemigram: A New Approach to Lensless Photography. Leonardo, 15(4), 262-268. doi:10.2307/1574733.

Crary, Jonathan. (1992). Techniques of the observer : on vision and modernity in the nineteenth century. MIT Press, Cambridge [Mass.]

Deleuze, Gilles and Félix Guattari. (1980). A Thousand Plateaus. Trans. Brian Massumi. London and New York: Continuum, 2004. Vol. 2 of Capitalism and Schizophrenia. 2 vols. 1972-1980. Trans. of Mille Plateaux. Les Editions de Minuit, Paris.

Foucault, Michel. (1977) "What is an Author" Language, Counter-Memory, Practice: Selected Essays and Interviews. Ed. Donald F. Bouchard. Cornell University Press, Ithaca, NY, 113-38.

Foucault, Michel. (2011) "Nietzsche, Soybilim, Tarih", içinde Felsefe Sahnesi, çev. Işık Ergüden, Ayrıntı Yayınları, İstanbul.

Goodfellow, lan; Pouget-Abadie, Jean; Mirza, Mehdi; Xu, Bing; Warde-Farley, David; Ozair, Sherjil; Courville, Aaron; Bengio, Yoshua (2014). Generative Adversarial Networks (PDF). Proceedings of the International Conference on Neural Information Processing Systems (NIPS 2014). pp. 2672-2680.

Jäger, G. (2005) 'Concrete Photography' In: Beate Reese, Jager Gottfried, and Rolf H. Krauss (ed.) Concrete Photography $=$ Konkrete Fotografie. Bielefeld: Kerber Verlag. pp.16-26.

Karras, T., Laine, S., \& Aila, T. (2019). A stylebased generator architecture for generative adversarial networks. In Proceedings of the IEEE/CVF Conference on Computer Vision and Pattern Recognition (pp. 4401-4410).

Karras, T., Laine, S., Aittala, M., Hellsten, J., Lehtinen, J., \& Aila, T. (2020). Analyzing and improving the image quality of stylegan. In Proceedings of the IEEE/CVF Conference on Computer Vision and Pattern Recognition (pp. 8110-8119). 
Krauss, Rosalind. (1977) Notes on the Index: Seventies Art in America. October 3, pp. 68-81.

Krauss, Rolf H. (2005) 'A Small History of Concrete Photography' In: Beate Reese, Jager Gottfried, and Rolf H Krauss (ed.) Concrete Photography = Konkrete Fotografie. Bielefeld: Kerber Verla

Li, W., Zhang, P., Zhang, L., Huang, Q., He, X., Lyu, S., \& Gao, J. (2019). Object-driven text-toimage synthesis via adversarial training. In Proceedings of the IEEE/CVF Conference on Computer Vision and Pattern Recognition (pp. 12174-12182).

Lyotard, J.-F., 1984 [1979], The Postmodern Condition: A Report on Knowledge, Geoff Bennington and Brian Massumi (trans.), University of Minnesota Press, Minneapolis.

Mounuddin, Skekh. (2019) The Political Twitterspace in India. Springer, Switzerland.
Parr, Martin and Gerry Badger. (2014) The Photobook: A History, volume I. Phaidon Press Limited, London.

Qiao, T., Zhang, J., Xu, D., \& Tao, D. (2019). Mirrorgan: Learning text-to-image generation by redescription. In Proceedings of the IEEE/CVF Conference on Computer Vision and Pattern Recognition (pp. 1505-1514).

Shaham, T. R., Dekel, T., \& Michaeli, T. (2019). Singan: Learning a generative model from a single natural image. In Proceedings of the IEEE/CVF International Conference on Computer Vision (pp. 4570-4580).

Warburton, Nigel. (2011) HackelBury fine art Pierre Cordier. Available at: http://www.hackelbury.co.uk/artists/cordier/cordier. html (Accessed: 20 October 2016). (Cited from Samara Knight, Camera-Less Photography: Can It Be Considered Photography?, University for the Creative Arts, BA (Hons) Photography Thesis, UK. 